\title{
Sharing Stories of Tragedy: Mapping Narratives of the Kent State Shooting
}

\section{Jennifer Mapes (she/her) \\ Kent State University \\ imapes@kent.edu}

Sara Koopman (she/her)

Kent State University

skoopman@kent.edu
On MAY $4^{\text {TH }}$, I970, in Kent, Ohio, the Ohio National Guard shot student protesters at Kent State University, killing four and wounding nine. It was a turning point in the history of the Vietnam War and underscored the importance of freedom of speech and the right to protest. Even 50 years later, debates continue regarding exactly what happened and who was to blame, as a divide remains between those who feel the shooting was unwarranted and others who think the protesters brought the violence onto themselves. Particularly in northeast Ohio, encouraging engagement with varied viewpoints is essential to promoting reconciliation.

Our goal is to do this by mapping stories told by those who experienced these events first hand: students, faculty, business owners, and other local residents, in an effort to create a dialogue among map users from a wide variety of backgrounds. These stories are drawn from oral histories collected by the Kent State Library and the Kent Historical Society. To share them with the broadest audience possible, we designed two maps. One is interactive, available at MappingMay4.Kent.edu, and allows users to add their own stories and reflections to the map. The other is a wall-sized print on display at the Kent Historical Society.

As both Kent State faculty and a city resident, I (Mapes) was motivated to create a mapping project that showed perspectives from the broader community. As I learned about the events of May 4, I realized that, while multiple

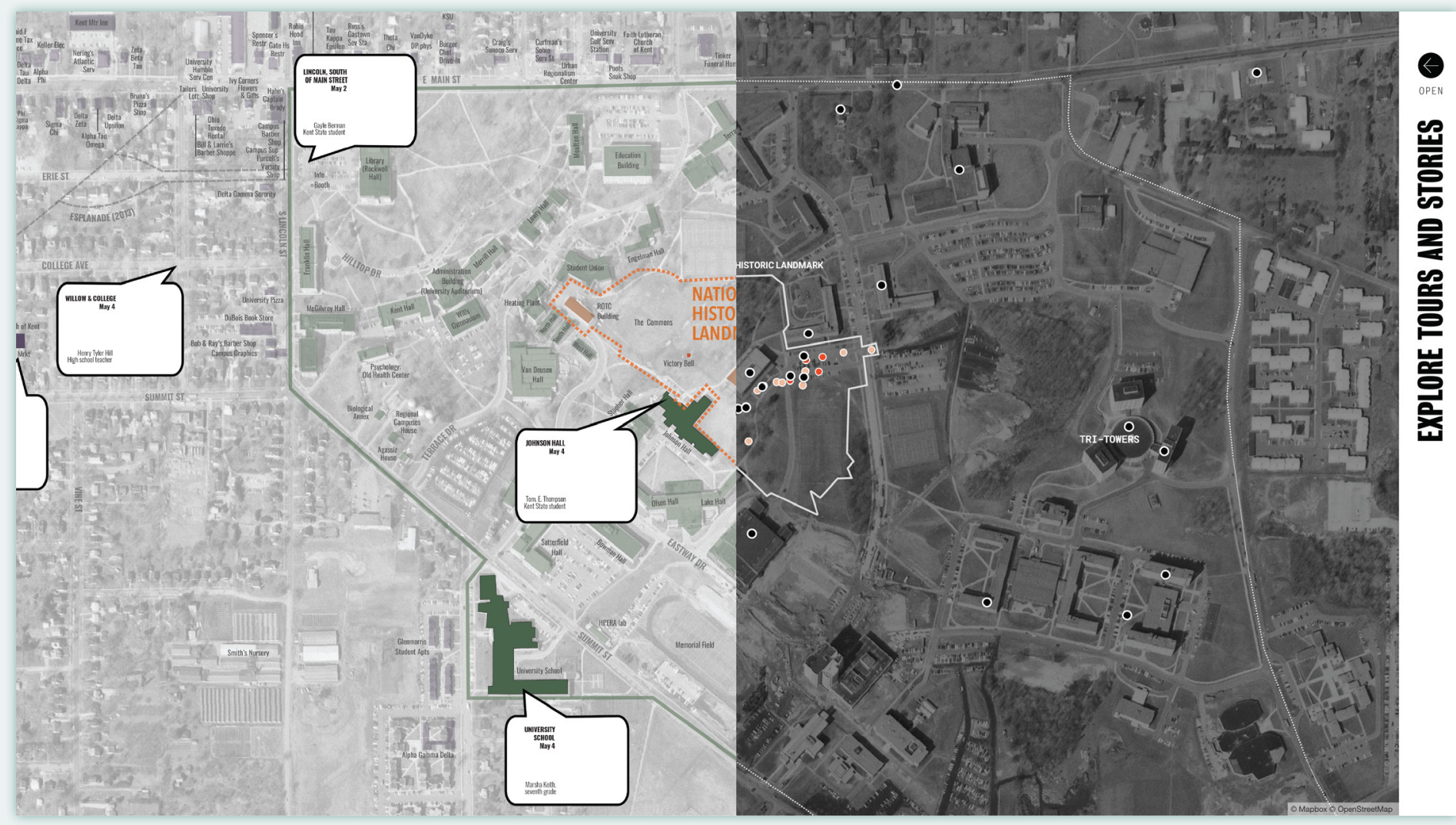

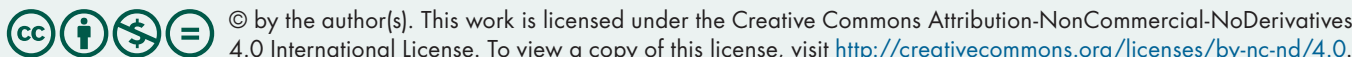


memorials were tied to the site of the shooting (a National Historic Landmark), little research and commemoration had focused on the events preceding the shooting in the broader campus/downtown area. Hundreds of photos and oral histories of May 1970 indicate the importance of understanding this broader site: student protesters frequently marched into downtown; the National Guard were called out due to unrest downtown during the weekend before May 4; an off-campus Students for a Democratic Society (SDS) house rattled the nerves of local residents; and after the shooting, the military occupation of campus and downtown increased tensions between the city, campus, and law enforcement. I saw the oral histories, tied to a map, as a way to document the fear and paralysis felt during these days both in the city and on campus.

Over dinner with a new colleague, Sara Koopman, a geographer working in our university's School of Peace \& Conflict Studies (established in 1971 as a "living memorial" to those killed in the shooting), we found a common interest in using maps to promote understanding and reconciliation in communities that have experienced trauma. We began to work together to build a website that could share stories of May $4^{\text {th }}$ with a broader audience. Since the spring of 2019, we have analyzed more than 130 oral histories in the university archives, along with more than 100 collected separately by the Kent Historical Society, to identify specific places described by interviewees. From the interviews, we collected stories about these places- "geo-narratives" that share individuals' experiences in a specific time and space. So far, we've found more than 300 stories in the oral histories that are connected to 100 specific locations. We then mapped each location-some were easy to find, but others involved research to figure out where places were located in 1970 . We also combed through university and community archives to find historical photos of these places, finding images that matched about 75 of the locations. One of the best sources turned out to be the university's yearbook, which was digitized a few years ago. But we also found newspaper clippings at the Historical Society and old postcards. We also added a basemap-a US Geological Survey aerial photograph taken on April 9, 1970-and identified all downtown businesses in 1970 using a reverse directory (which allows looking up the name of a business located at a particular address).

From a cartographic perspective, our goal was to simplify a large amount of spatial data and make it accessible to a diverse audience. There is no lack of information on the Kent State shooting, and our library's special collections, paired with those of the Historical Society, were filled with photos, newspaper clippings, maps, and written and spoken histories. But as they are housed and configured, many of these data are not easy to access. For example, though digitized, the oral histories are often at least an hour long and are very particular to an individual's experiences. One of our key audiences, those who were young adults in the 1970s, is also sometimes not digitally savvy. Our goal was to take these stories and reshape them to be more easily heard and shared by people of all ages.

Access to both an aerial photograph from 1970 and reverse directory data served as an impetus for a static map. When I mentioned this idea to the May 4 collection librarian, she suggested that a map like this would also be a great way to help those being interviewed remember and share their story. But the map's size posed challenges. Originally provided to interviewees as a $24 \times 36$ inch poster, those giving oral histories (often in their 70s) found this unwieldy, so I reformatted it to multiple, tiled, $8 \times 11$ maps of the city and campus.

The next step for this map was to create a large version that could promote broader public engagement. We originally envisioned a "talking wall" where an interactive map was projected onto a wall in downtown Kent. This was pared down to two exhibits, one at the Historical Society, and another at the campus's May 4 Visitor Center, a wallpaper-like map $(9 \times 7 \mathrm{ft})$ with buttons on specific locations that play short audio clips of stories.

The big map had some restrictions: labels, even for the clustered downtown businesses, needed to be large enough

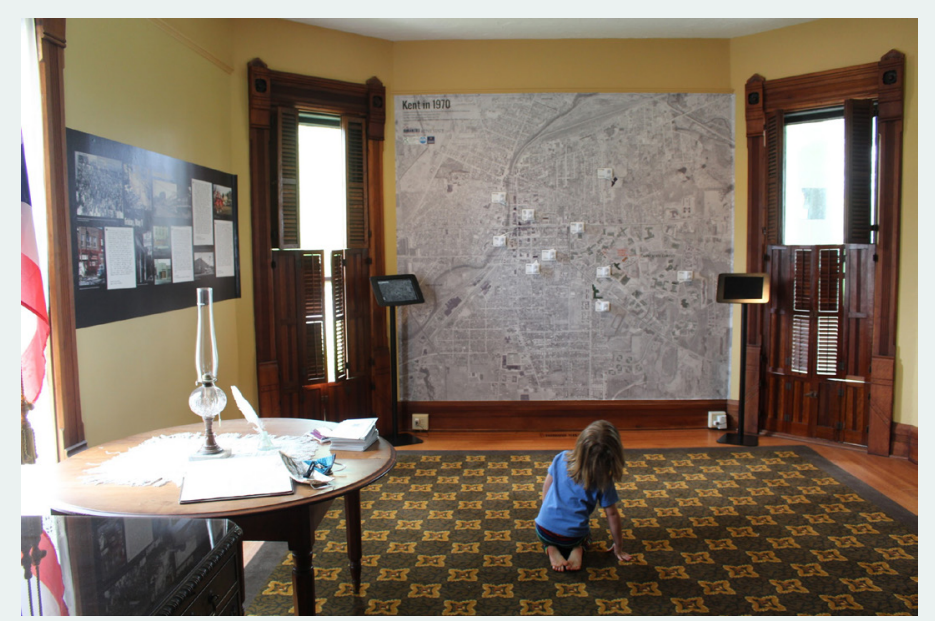



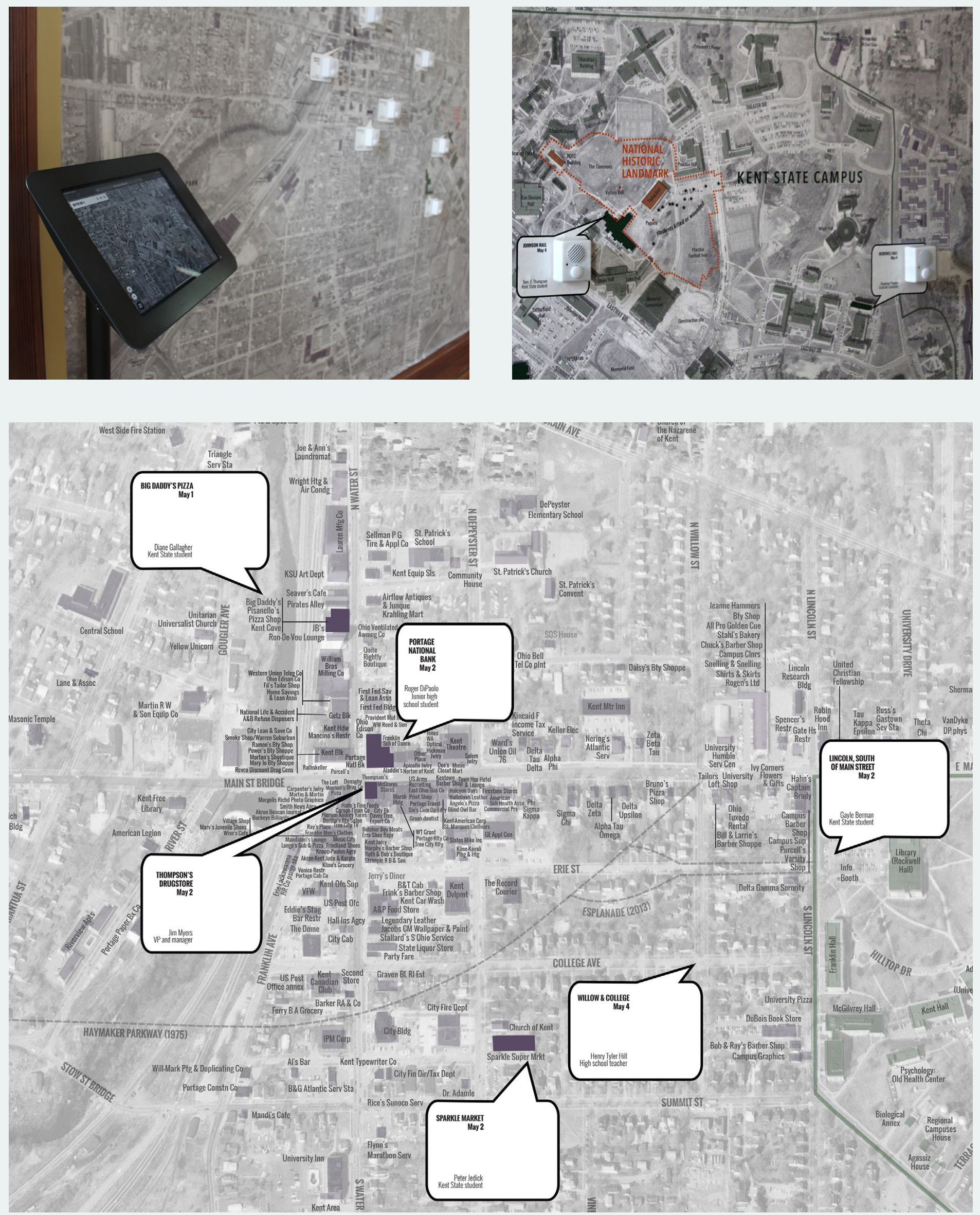

The wall map. 
to be legible from a distance. It needed to show landmarks familiar to long-term residents, but not so many that it was cluttered. In the end, I (Mapes) decided to add building footprints only to businesses for which we had 1970 names, and the aerial photograph was lightened so as not to distract from more important elements. Highlighted story locations and overall scale were chosen strategically, so that they didn't require users to reach too high or low; while the map was nine feet high, most of the key features needed to be at eye level, within three to six feet from the floor. I also worked around some temporal issues by setting most of the map in 1970, but adding four key post1970 Kent landmarks: two highway bypasses (Haymaker Parkway and SR 261), a new bridge, and an outline of the National Historic Landmark. We also chose to add the locations where students were wounded and killed in the shooting to provide context for those new to the story and geography.
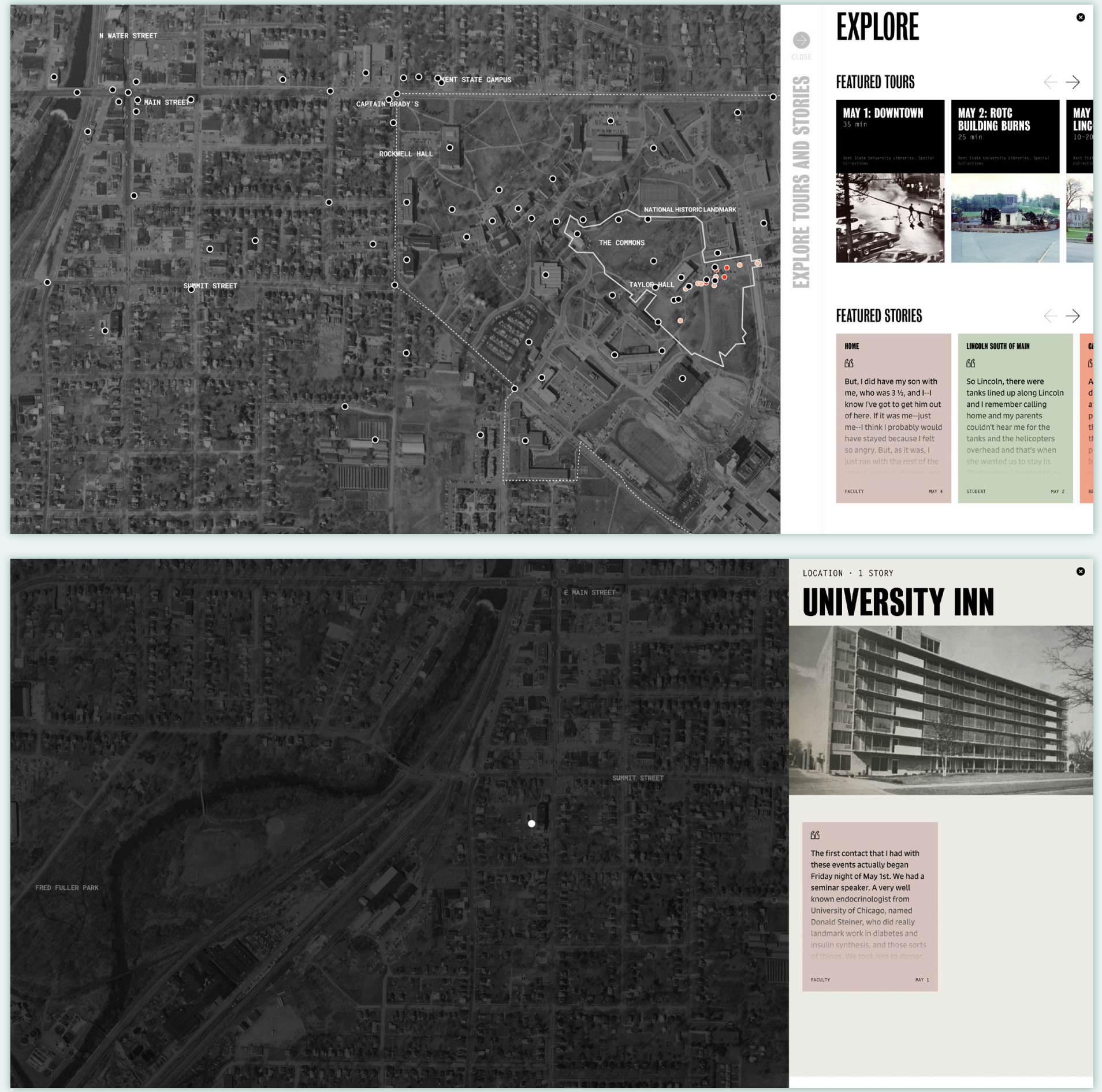

\section{UNIVERSITY INN}
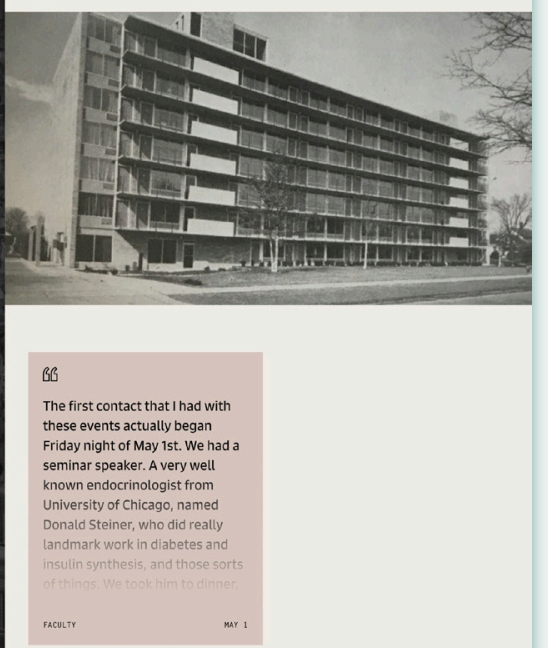


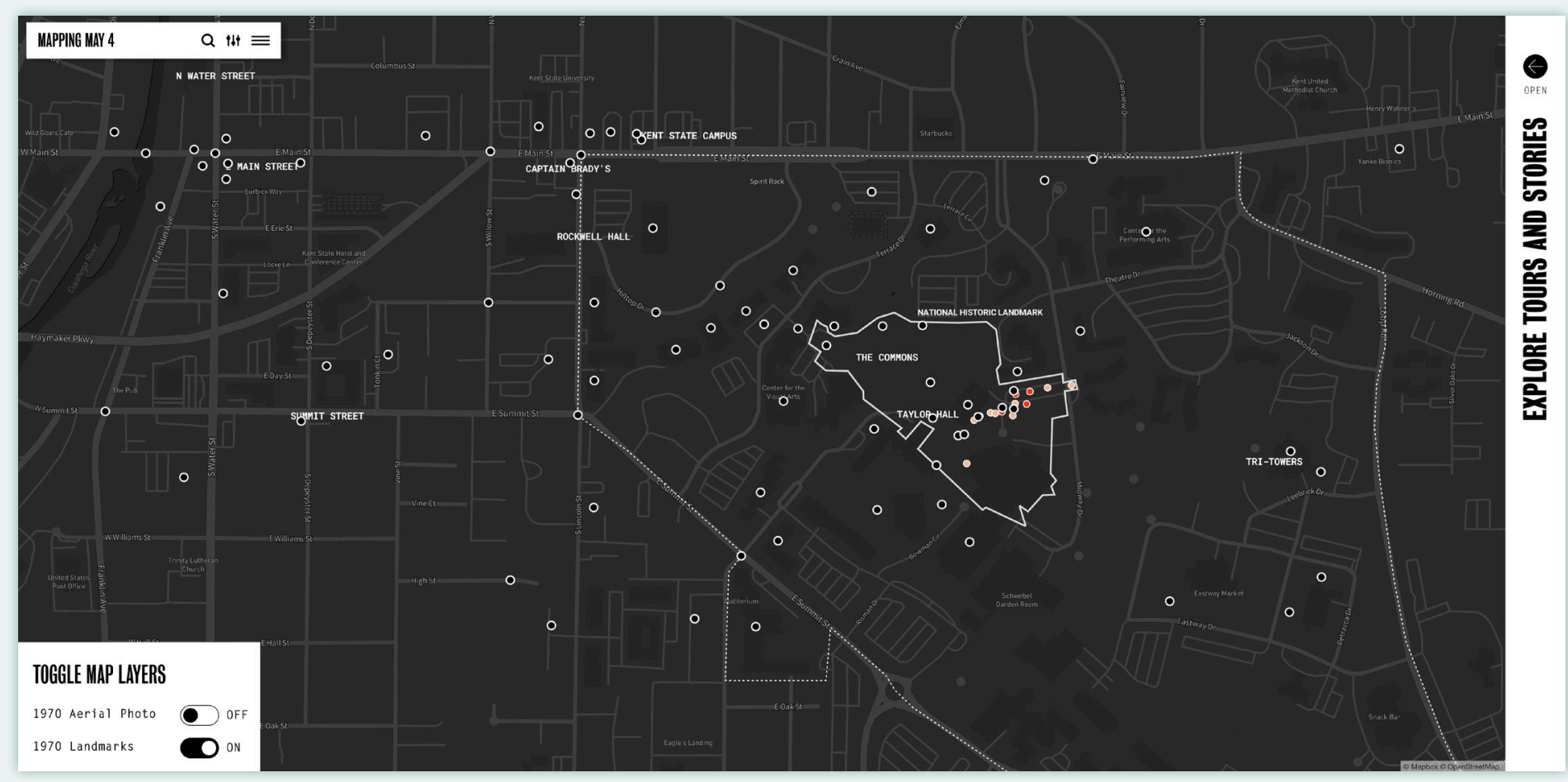

To produce the interactive website, we worked with a local design firm, Each + Every, who helped us decide on the look and feel of the map and developed the code behind it. The first version of the website used the Google Maps API, but when we received additional funding (from Kent State University and Ohio Humanities), I recommended we switch to Mapbox to allow for improved tiling of the aerial photo and the creation of a more stylized basemap. Overall, we decided on a design that was mostly greyscale, to let the images and stories speak louder than the map itself.

As with the static map, there were basemap challenges with the dynamic map. Users ranged from those who only knew the Kent of 1970, to those who only know today's Kent, to people who had never visited but wanted to learn
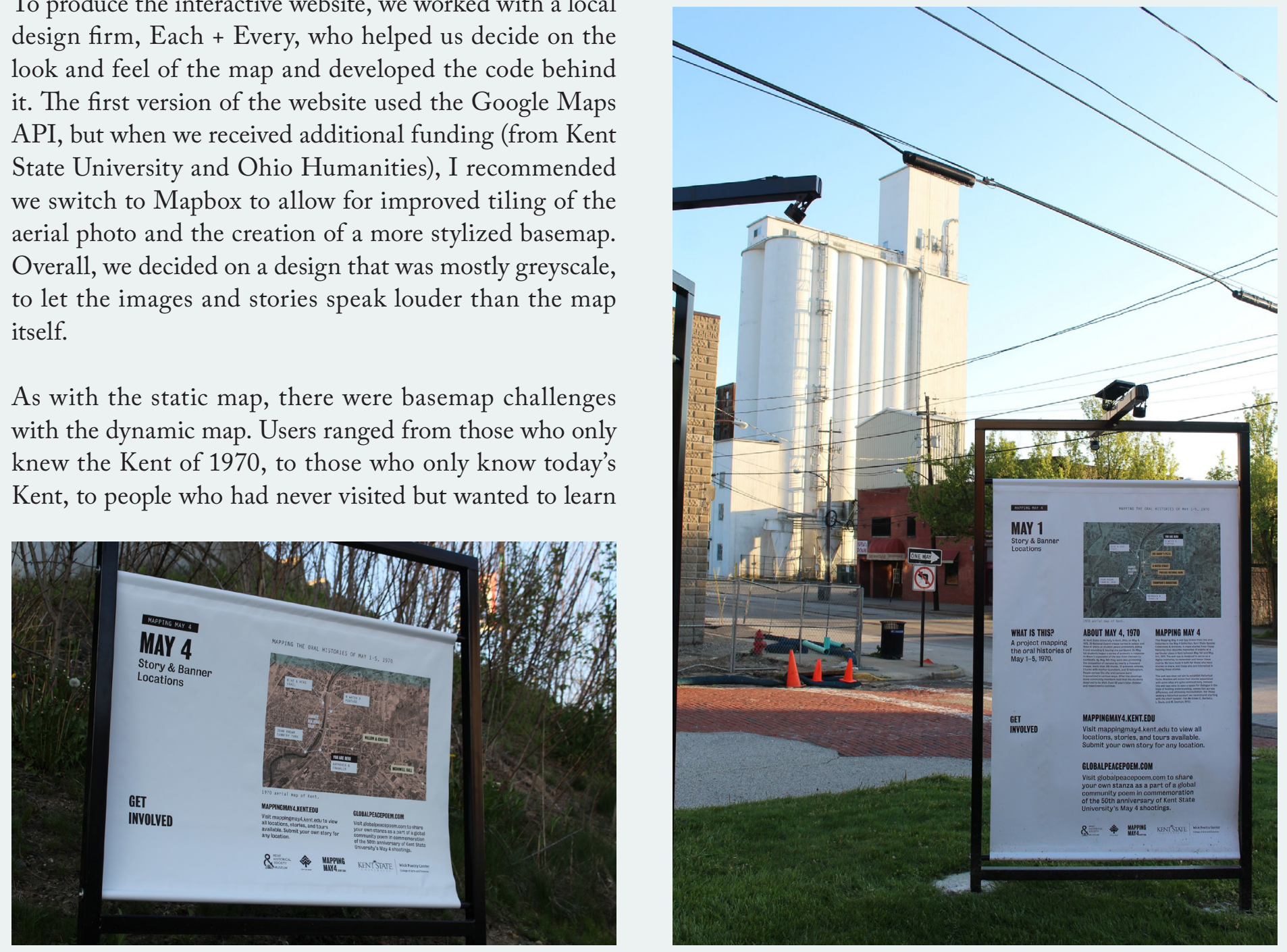

Outdoor exhibits. 
more about the shooting. We ended up not including a lot of detail but adding a search function that would let those with memories tied to specific places search for these locations. A few landmarks were labeled (streets, the campus boundary), but we relied heavily upon a hover feature to add context for those browsing the map, without creating clutter.

Our initial hope was to create an app that would "ping" the user when they walked by a site with a story. This proved difficult to program, but we created a location-aware site that shows the sites closest to users on smartphones, and offers walking tours based on each day of the events leading up to and including the shooting. We also let users add their own stories and reflections to existing or new places on the map with text, audio, photo, or video. This interactive feature of the map is essential to creating a dialogue between users and across history, and was particularly important when our in-person tours were postponed due to the pandemic.

The second version of the website was released in April 2020 , timed to coincide with the $50^{\text {th }}$ anniversary of the shooting. Over the May 1-4 weekend, we had 1,631 users, and nearly 3,000 overall between April and August 2020. While users came from 44 different countries, nearly half were from Northeast Ohio. The main cartographic parts of this project are complete, but we continue to add stories as more oral histories are recorded and archived, and to reach out to a broader audience by developing lesson plans for high school and college students. 